\title{
PENINGKATAN PELAYANAN JASA KONSULTAN LINGKUNGAN HIDUP DENGAN PENGEMBANGAN WEBSITE CV FAHMI JAYA
}

\author{
Yulindawati $^{1}$, Ita Arfyanti ${ }^{2}$ \\ STMIK Widya Cipta Dharma ${ }^{1,2}$ \\ JL. Prof. M. Yamin No. 25 Samarinda \\ Sur-el : linda@wicida.ac.id ${ }^{1}$, ita@ wicida.ac.id ${ }^{2}$
}

\begin{abstract}
Research on the improvement of environmental consulting services with the development of the CV website. Fahmi Jaya is a research to make it easier for the public to obtain complete and up-to-date information because information is felt to be very important in making decisions and in achieving goals. In addition to obtaining complete and up-to-date information, the website can also send and publish information to the wider community online. The system development method used in this research is the System Development Life Cycle (SDLC) method, or better known as the system development life cycle in system engineering and software engineering, is the process of making and changing systems and the models and methodologies used to develop these systems. The results of the research are expected that this system can publish its activities for more recent information so that the public can find out the activities that have been carried out, the ease of information about CV FAHMI JAYA.
\end{abstract}

Keywords:Website, SDLC, CV Fahmi Jaya

\begin{abstract}
Abstrak : Penelitian peningkatan pelayanan jasa konsultasi lingkungan hidup dengan pengembangan website CV Fahmi Jaya merupakan penelitian untuk mempermudah masyarakat memperoleh informasi yang lengkap dan terbaru karena informasi di rasa sangat penting dalam pengambilan keputusan dan dalam mencapai tujuan. Selain memperoleh informasi yang lengkap dan terbaru, website juga dapat mengirim serta mempublikasikan informasi kepada masyarakat luas secara online. Metode Pengembangan sistem yang digunakan penelitian yaitu metode (SDLC) System Development Life Cycle atau yang lebih dikenal siklus hidup pengembangan sistem dalam rekayasa sistem dan rekayasa perangkat lunak adalah proses pembuatan dan pengubahan sistem serta model dan metodologi yang digunakan untuk mengembangkan sistemsistem tersebut. Hasil penelitian diharapkannya sistem ini dapat mempublikasikan kegiatannya untuk informasi yang lebih terbaru lagi sehingga masyarakat dapat mengetahui kegiatan-kegiatan yang telah dilakukan, kemudahan informasi tentang CV FAHMI JAYA.
\end{abstract}

Kata kunci: Website Profile, SDLC, CV Fahmi Jaya

\section{PENDAHULUAN}

Saat ini adalah zamannya internet di mana batasan waktu dan jarak tidak berarti lagi bagi media yang satu ini. Kita dapat berkomunikasi dengan siapa saja dan di mana saja di seluruh dunia ini dengan menggunakan fasilitas e-mail maupun dengan cara chatting. Mungkin pada saat ini hampir setiap orang sudah memiliki $e$ mail untuk dapat bergabung di internet[1].
Sejak didirikan tahun 2015 CV FAHMI JAYA mempunyai salah satu masalah yaitu menyangkut tentang penyediaan informasi untuk mengetahui informasi dari jasa konsultan terhadap lingkungan hidup. Salah satu faktor untuk membangun website pada CV FAHMI JAYA agar dapat mempermudah pada pengguna jasa konsultasi dari dalam maupun luas Samarinda untuk mengetahui informasi dari jasa konsultasi dan alamat perusahaan. 


\section{METODOLOGI PENELITIAN}

Metode penelitian dalam peningkatan pelayanan jasa konsultan lingkungan hidup dengan pengembangan website $\mathrm{CV}$ Fahmi Jaya adalah sebagai berikut:

\subsection{Informasi}

Informasi adalah data yang telah diklasifikasi atau diolah atau diinterpretasikan untuk digunakan dalam proses pengambilan keputusan[2]. Informasi merupakan hasil olah data, di mana data tersebut sudah diproses dan diinterpretasikan menjadi suatu pengetahuan yang bermakna untuk pengambilan keputusan[3].

\subsection{Web}

Website atau situs web merupakan sebutan bagi sekelompok halaman web (web page). Sebuah situs web diakses dari sebuah URL (Uniform Resource Locator) yang menjadi “akar” (root)[4].

\subsection{Internet}

Internet adalah suatu media informasi komputer global yang dapat di katakan sebagai teknologi tercanggih abad ini. Secara etimologis, Internet berasal dari Bahasa inggris, yakni inter berarti antar dan net berarti jaringan sehingga dapat kita artikan hubungan antar jaringan[5].

\subsection{MySQL}

MySQL atau dibaca "Myskuel" dengan adalah suatu RDBMS (Relational Data Base Management System) yaitu aplikasi sistem yag menjalakan fungsi pengolahan data. MySQL pertama dikembangkan oleh MySQL AB yang kemudian diakuisisi Sun Microsystem dan terakhir dikelola oleh Oracle Coorporation[6].

\subsection{Basis Data (Database)}

Berikut beberapa Pengertian tentang Basis data, yaitu[7]:

1. Kumpulan terpadu dari elemen data logis yang saling berhubungan Basis Data Mengkonsolidasikan banyak catatan yang sebelumnya di simpan dalam file terpisah.

2. Merupakan suatu kumpulan data yang berhubungan secara logis dengan deskripsi data tersebut, yang dirancang untuk memenuhi informasi yang dibutuhkan oleh suatu organisasi. Artinya, basis data merupakan tempat penyimpanan data yang besar, di mana dapat digunakan oleh banyak pengguna. Seluruh item basis data tidak lagi dimiliki oleh satu departemen, merupakan menjadi sumber daya perusahaan yang dapat digunakan bersama.

\subsection{Tahapan Pengembangan Sistem}

Metode pengembangan sistem yang digunakan dalam penelitian ini adalah sebagai berikut:

1. Analisis

Pada tahap ini dilakukan analisis terhadap aplikasi atau sistem yang akan dibangun berikut ini adalah beberapa analisis yang perlu di lakukan membangun website company profile pada CV FAHMI JAYA[8]:

a. Diagram Konteks

Pada Gambar 1. Diagram konteks merupakan level tertinggi dari Diagram Flow Data (DFD) yang menggambarkan seluruh input ke atau dari sistem yang memberikan gambaran 
tentang keseluruhan sistem[9]. Pada Gambar 1. Merupakan diagram konteks dari pembuatan website company profile pada CV FAHMI JAYA.

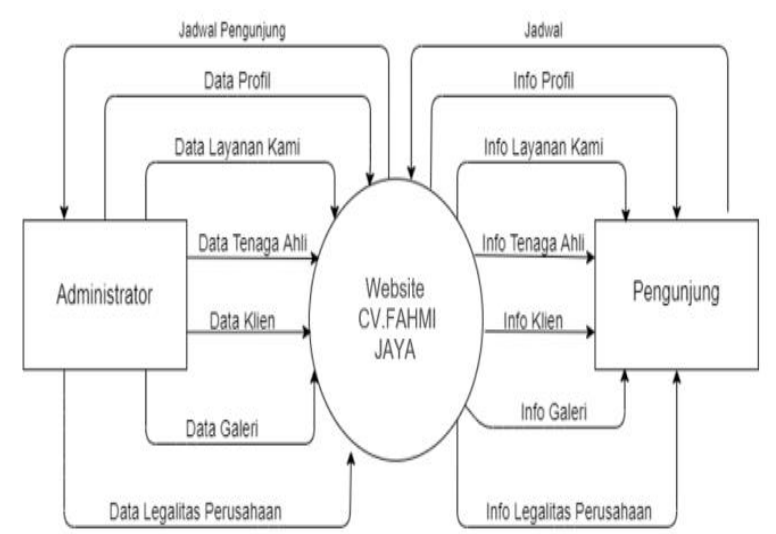

Gambar 1. Diagram Konteks

\section{b. Flowchart Sistem}

Pada Gambar 2. menjelaskan bahwa pada saat user menggunakan website ini, maka user dapat mengisi form pada halaman kontak untuk membuat janji pertemuan dengan pihak perusahaan. Kemudian sistem akan memproses data yang masuk. Setelah data diproses dan telah tersimpan pada database sistem, maka sistem akan menampilkan pesan bahwa jadwal meeting telah ditentukan

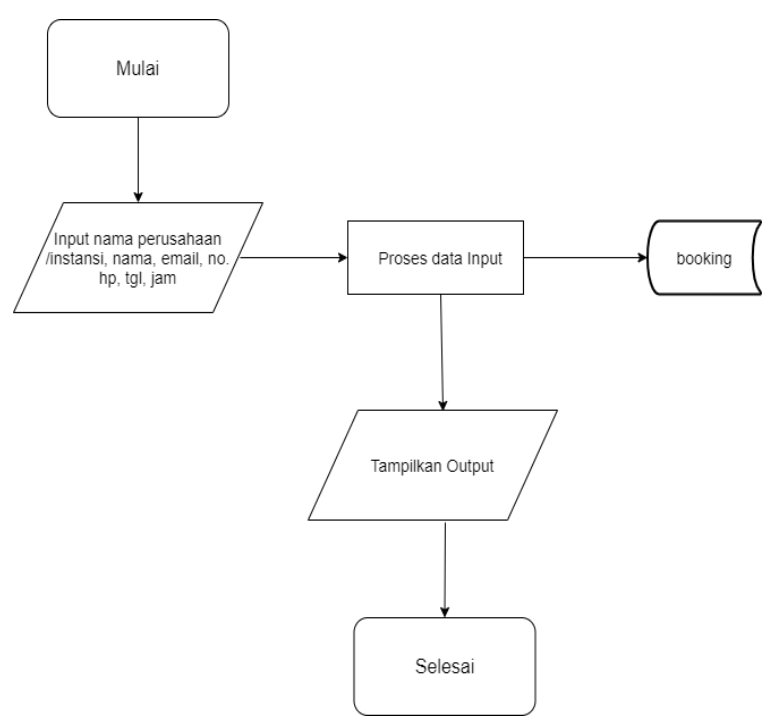

Gambar 2. Flowchart Sistem c. Site Map User

Pada Gambar 3. Site map secara langsung menggambarkan hierarki website melalui hubungan tiap link-link dari setiap menu website[10][11].

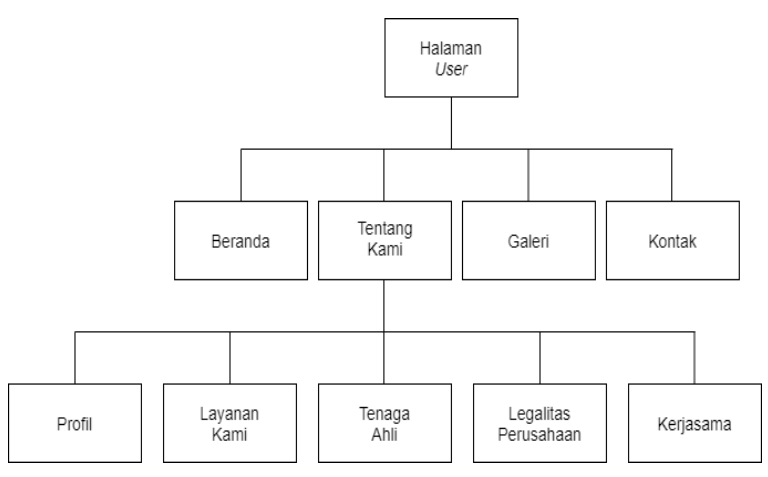

Gambar 3. Site Map User

d. Site Map Administrator

Pada Gambar 4. Menerangkan alur pada sistem admin yang terdiri dari beranda yaitu halaman depan admin dan menu memiliki submenu yaitu tentang profil layanan kami, tenaga ahli, legalitas perusahaan dan klien, halaman dapat melihat data dan menambahkan data galeri dapat menambahkan data dan melihat data.

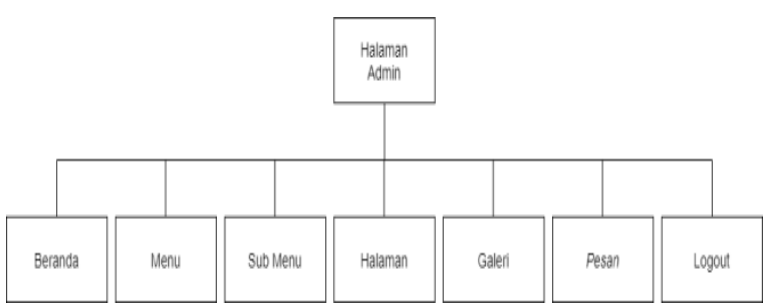

Gambar 4. Site Map Administrator

\section{Desain Sistem}

Desain sistem merupakan salah satu bagian yang sangat penting dalam penyusunan laporan penelitian ini, pada sebuah desain sistem akan dilihat fungsi dan peran masing-masing data yang terkumpul dalam membentuk sebuah sistem/program[12], desain sistem yang digunakan dalam penelitian ini adalah Struktur 
Database. Struktur basis data dimaksudkan untuk mengidentifikasi kebutuhan yang diperlukan[13][14]. Adapun struktur basis data yang diperlukan dalam membangun sistem atau aplikasi adalah:

\section{a. Tabel User}

Tabel 1 adalah tabel user dimana digunakan untuk pemeliharaan data user, tabel user ini memiliki primary key yaitu field "Id_user". Untuk melihat struktur tabel user dapat dilihat pada tabel 1.

Tabel 1. Tabel Struktur User

\begin{tabular}{ccc}
\hline No & Nama Field & Type \\
\hline 1 & Id_user & Int(5) \\
2 & Username & Varchar(50) \\
3 & Password & Varchar(50) \\
\hline
\end{tabular}

\section{b. Tabel Menu}

Tabel 2 adalah tabel menu di mana digunakan untuk menyimpan data menu yang ada pada halaman admin, tabel menu ini memiliki primary key yaitu field "Id_menu". Untuk melihat struktur tabel menu dapat dilihat pada tabel 2 .

\section{Tabel 2. Tabel Struktur Menu}

\begin{tabular}{ccc}
\hline No & Nama Field & Type \\
\hline 1 & Id_menu & Int $(5)$ \\
2 & Judul & Varchar(50) \\
3 & Tanggal & Date \\
4 & Urutan & Int $(3)$ \\
\hline
\end{tabular}

\section{c. Tabel Sub-menu}

Tabel 3 adalah tabel sub menu di mana digunakan untuk menyimpan data sub menu pada halaman admin, tabel menu ini memiliki primary key yaitu field "Id_submenu". Untuk melihat struktur tabel sub menu dapat dilihat pada tabel 3 .

\section{Tabel 3. Tabel Struktur Submenu}

\begin{tabular}{ccc}
\hline No & Nama Field & Type \\
\hline 1 & Id_submenu & $\operatorname{Int}(5)$ \\
2 & Id_menu & $\operatorname{Int}(5)$ \\
3 & Judul & $\operatorname{varchar}(50)$ \\
4 & Ururtan & $\operatorname{Int}(3)$ \\
\hline
\end{tabular}

\section{d. Tabel Galeri}

Tabel 4 adalah tabel galeri di mana digunakan untuk menyimpan foto-foto, tabel galeri ini memiliki primary key yaitu field "Id_galeri". Untuk melihat struktur tabel galeri dapat dilihat pada tabel 4 .

Tabel 4. Tabel Struktur Galeri

\begin{tabular}{ccc}
\hline No & Nama Field & Type \\
\hline 1 & Id_galeri & Int $(5)$ \\
2 & Judul & Varchar(100) \\
3 & Gambar & Varchar(100) \\
4 & Tanggal & Date \\
\hline
\end{tabular}

e. Tabel Halaman

Tabel 5 adalah tabel halaman di mana digunakan untuk menampung file halaman, tabel halaman ini memiliki primary key yaitu field "Id_halaman". Untuk melihat struktur tabel halaman dapat dilihat pada tabel 5 .

\section{Tabel 5. Tabel Struktur Halaman}

\begin{tabular}{ccc}
\hline No & Nama Field & Type \\
\hline 1 & Id_halaman & $\operatorname{Int}(11)$ \\
2 & Judul & $\operatorname{Varchar}(50)$ \\
3 & Isi & Text(50) \\
\hline
\end{tabular}

\section{f. Tabel Booking}

Tabel 6 adalah tabel booking di mana digunakan untuk menampung semua file booking, tabel booking ini memiliki primary key yaitu field "Id_booking". Untuk melihat struktur tabel booking dapat dilihat pada tabel 6 . 
Tabel 6. Tabel Struktur Booking

\begin{tabular}{ccc}
\hline No & Nama Field & Type \\
\hline 1 & Id_booking & Int(11) \\
2 & Nm_inst & Varchar(50) \\
3 & Nama & Varchar(50) \\
4 & Email & Varchar(50) \\
5 & No_hn & Char(14) \\
6 & Tanggal & Date \\
7 & Jam & Time \\
\hline
\end{tabular}

\section{HASIL DAN PEMBAHASAN}

Gambar 5. Terdapat proses awal untuk dapat mengakses pada halaman index pengunjung, berikutnya dalam halaman index pengunjung ini terdapat informasi - informasi yang di-update oleh admin, sehingga pengunjung mengetahui berita atau informasi terbaru tentang CV FAHMI JAYA.

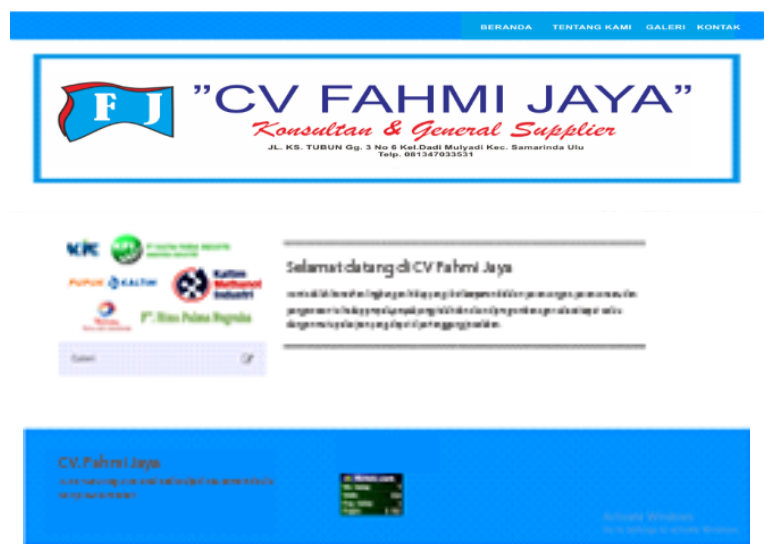

Gambar 5. Halaman Utama Website

Pada Gambar 6, merupakan halaman galeri yang dapat dilihat pengunjung yang berisikan foto tentang kegiatan seperti survey dan lainnya.

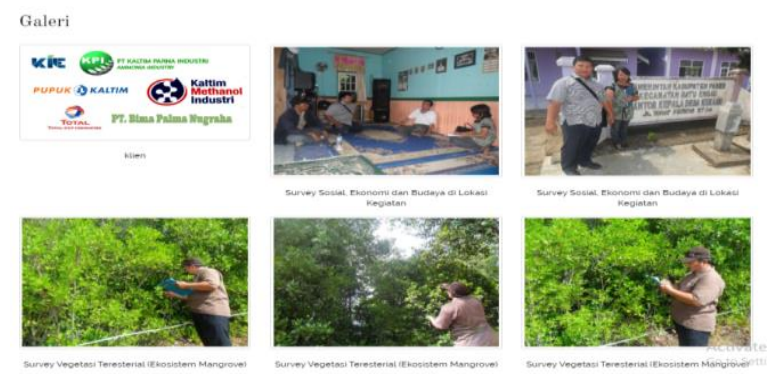

Gambar 6. Halaman Galeri
Pada Gambar 7. Merupakan halaman pertama admin untuk masuk ke dalam halaman utama admin, dimana password dan username harus sesuai dengan apa yang telah di buat di dalam database admin.

\section{Login Admin}

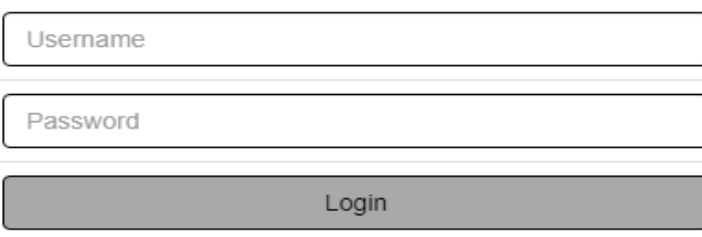

\section{Gambar 7. Halaman Login Admin}

Pada Gambar 8. Merupakan halaman admin yang dapat dikunjungi oleh admin utama CV FAHMI JAYA di mana admin dapat melakukan semua kegiatan pada halaman website seperti halnya meng-update informasi, foto-foto serta menambahkan data, menghapus edit dan lain-lain.

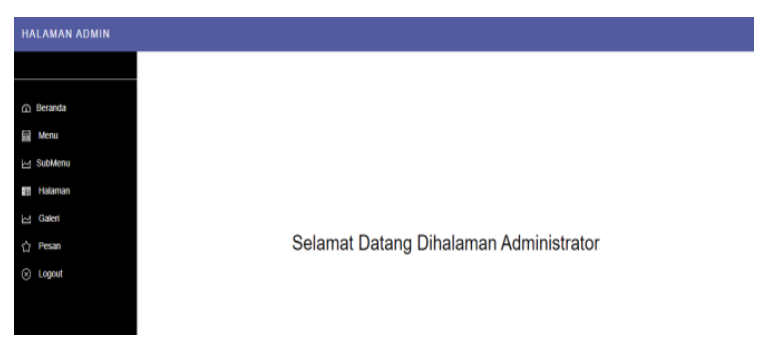

\section{Gambar 8. Halaman Utama Admin}

\section{KESIMPULAN}

Dengan adanya website ini, informasi layanan dari CV FAHMI JAYA dapat diketahui banyak orang, baik dari Samarinda maupun luar Samarinda dan dengan demikian informasi dapat dilihat oleh semua orang. Website ini juga pengunjung dapan membuat janji temu dengan pihak CV FAHMI JAYA untuk berkonsultasi maupun membuat kontrak kerja sama. 
Diharapkan juga adanya pengembangan terhadap website ini agar dapat menjadi sebuah website yang lebih lengkap lagi, yang dapat memudahkan penjunjung untuk mendapatkan informasi dan memberikan minat dari pengunjung yang ingin mendapatkan informasi mengenai CV FAHMI JAYA.

\section{UCAPAN TERIMA KASIH}

Publikasi ini dibiayai oleh Direktorat Riset dan Pengabdian Masyarakat Direktorat Jenderal Penguatan Riset dan Pengembangan Kementerian Riset dan Teknologi/ Badan Riset dan Inovasi Nasional sesuai dengan Kontrak Penelitian Tahun Anggaran 2021.

\section{DAFTAR PUSTAKA}

[1] Abdulloh., Web Programming Is Easy, Jakarta : PT. Elex Media Komputindo. 2015.

[2] AS., Rosa dan Shalahuddin, M., Rekayasa Perangkat Lunak Terstruktur Dan Berorientasi Objek. Informatika. Bandung. 2013.

[3] Hakim., Sistem Penilaian dalam Kurikulum 2013: Kajian Dokumen Terhadap Kurikulum 2013. 2013.

[4] Hidayatullah, Priyanto., Visual Basic .NET, Edisi Revisi. Bandung: Informatika. 2014.

[5] Puspitosari, Heni A., Pemrograman Web Database dengan PHP dan MySQL Tingkat Lanjut. Penerbit : Skripta. 2010.

[6] Ardhana, YM Kusuma., PHP menyelesaikan Web 30 Juta!, Jakarta: Jasakom. 2012.

[7] Hutahaean, J., Konsep Sistem Informasi. Yogyakarta: CV Budi Utama.

[8] Jogiyanto, H. M. Analisis dan Rancangan Sistem Informasi: pendekatan terstruktur teori dan praktek aplikasi bisnis. Yogyakarta: Andi Offset. 2010.

[9] Indrajani., Pengantar Sistem Basis Data Case Study All In One. Jakarta : Elex Media Komputindo. 2014.
[10] Sibero, Alexander F.K. Web Programing Powerpack: MediaKom. 2013.

[11] Jauhari, Khairul., Step by step : Web Design Theory and Practice. 2014.

[12] Setyaputra, Lukas., Buat Situs Gaul dengan Jomla, Yogyakarta : Skripta. 2010.

[13] Ferdiansyah, M. S., Jasri, M., \& Widjianto, W. Aplikasi Quick Response Dalam Melayani Pengaduan Kerusakan Sarana Stt Nurul Jadid Berbasis Android dan Web. 2016.

[14] Antonio, H., \& Safriadi, N. Rancang Bangun Sistem Informasi Administrasi Informatika. 2012. 